\title{
Tumor de células granulares en esófago Presentación de caso y revisión de literatura.
}

\section{Esophageal granular cell tumor Case presentation and literature review.}

Pág. 18,23

Recibido: 06-05-2020

Dr. Nicole Caro Porras ${ }^{1}$.

Aceptado: 08-06-2020

Dr. Marianela Alvarado Salazar².

1. Médico residente, Caja Costarricense del Seguro Social. Costa Rica.

2. Médico especialista en Gastroenterología. Caja Costarricense del Seguro Social. Costa Rica.

\section{RESUMEN}

El tumor de células granulares o de Abrikossoff es un tumor infrecuente. Usualmente es benigno, pero existen casos documentados de malignidad. Puede encontrarse en cualquier localización anatómica, y se sabe que posee derivación neural. Un 4-6\% se localiza en el tracto gastrointestinal y un tercio de ellos, en esófago. Es un tumor usualmente asintomático, por lo que la mayoría se diagnostica en endoscopías realizadas por otras causas. La edad de diagnóstico es alrededor de los 30-60 años. Macroscópicamente, se observa como una masa sésil, firme, blanco-amarillenta y está localizada principalmente en submucosa. A la histología e inmunohistoquímica se documenta granulaciones y positividad para S-100 y PAS diastasa resistente. En este trabajo se presenta un caso de tumor de células granulares de esófago con características típicas descritas en la literatura, diagnosticado en el Hospital
Escalante Pradilla. A nuestro conocimiento, es el primer tumor de Abrikossoff de esófago reportado en Costa Rica.

\section{PALABRAS CLAVE}

Tumor de células granulares; esófago; tracto gastrointestinal; inmunohistoquímica. Fuente DeCS.

\section{ABSTRACT}

Granular cell tumor or Abrikossoff's tumor, is uncommon. It is usually benign, although there are some malignant tumors reported. It can be located anywhere in the body and is believed that it has a neural origin. About $4-6 \%$ are located in the gastrointestinal tract, and one third of them, in the esophagus. It is usually an asymptomatic tumor, most of the time diagnosed in endoscopies conducted by other causes. The age of diagnosis is around $30-60$ years. On 
gross examination, it is seen as a sessile, firm, yellowish-white mass and is located mainly in submucosa. Granulations and positivity for S-100 and diastase resistant PAS are documented in immunohistochemistry and histology. In this paper, we present a case of granular cell tumor of the esophagus with typical characteristics diagnosed in Escalante Pradilla Hospital. To our knowledge, it is the first Abrikossoff esophageal tumor reported in Costa Rica.

\section{KEY WORDS}

Granular cell tumor, esophagus, gastrointestinal tract; immunohistochemistry. Source DeCS.

\section{Introducción}

El tumor de células granulares o de Abrikossoff es un tumor poco común, y la mayoría de literatura se basa en reportes de casos o series de casos. Se puede localizar en cualquier parte del cuerpo, incluido el esófago, que corresponde al sitio más común de aparición en el tracto gastrointestinal (1). Desde 1931, cuando se describió por primera vez un tumor de células granulares en esófago, por el mismo Abrikossoff, hasta el año 2014, se han descrito tan solo 350 reportes de caso a nivel mundial $(2,3)$. Es un tumor que presenta un origen neural, tal como lo comprueba la inmunohistoquímica y en la mayoría de casos, presenta un comportamiento benigno $(4,5)$.

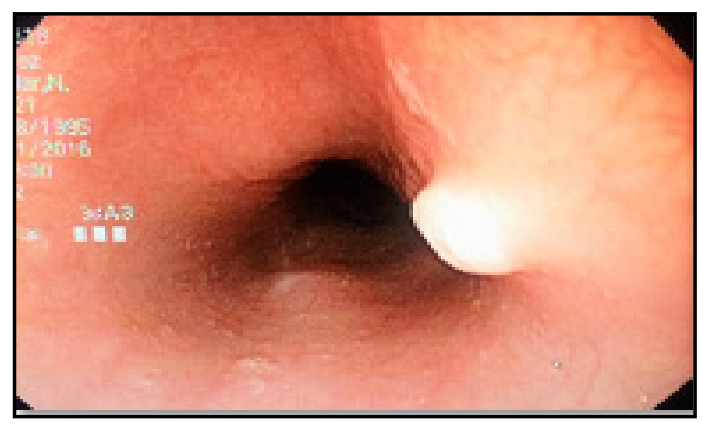

Figura 1 Visión Endoscópica. Se observa un pólipo sésil, firme, blanco-amarillento en la pared del esófago
En este trabajo, se reporta un caso de tumor de células granulares en esófago,diagnosticado en el Hospital Escalante Pradilla en Costa Rica y se realiza una revisión de la literatura.

\section{CASO CLÍNICO}

Paciente femenina de 21 años, vecina de San Vito de Puntarenas, se presenta a la consulta del Hospital de Ciudad Neilly por estudio de gastritis crónica, asintomática. Se realiza una gastroscopía que evidencia en tercio medio de esófago una lesión polipoide, sésil, de color amarillo, la cual se biopsea (Figura 1) y además se realiza mucosectomía endoscópica. La biopsia se envía al Hospital Escalante Pradilla para su análisis. Al examen histológico se observa proliferación de células poligonales, dispuestas en nidos de citoplasma amplio, acidófilo, granular, de núcleos pequeños y redondos. Con tinción de PAS diastasa resistente, muestran positividad para las granulaciones y positividad para S-100. No se evidencia atipia, necrosis, ni figuras de mitosis (Figura2).

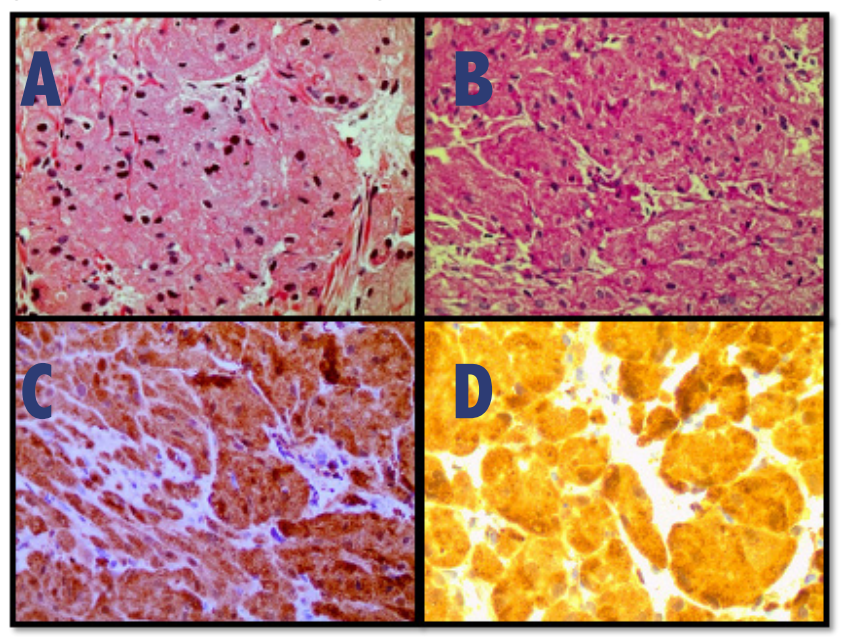

Figura2: Imágenes microscópicas del tumor de células granulares. A. Tinción de Hematoxilina eosina, muestra células de citoplasma amplio, granular con núcleo pequeño, uniforme, hipercromático. B. PAS diastasa resistente. C. Positividad para S-100. D. Positividad para enolasa neuroespecífica. 
Un año después, se repite gastroscopía sin evidencia macroscópica de recidiva y a nivel microscópico con toma de biopsias no se evidencia la presencia de células neoplásicas pero sí la presencia de gastritis crónica sin atrofia, sin actividad aguda y con helicobacter pylori. La paciente continúa libre de recidiva y asintomática.

\section{DISCUSIÓN}

El tumor de células granulares fue descrito por primera vez en 1926 por Abrikossoff, un médico patólogo ruso, quien reportó una serie de 5 casos de pacientes que presentaban tumores en la lengua (2). Al inicio lo describió como un mioblastoma, porque presentaba una morfología similar al músculo estriado (6). Con el paso del tiempo, las pruebas realizadas a los tumores permitieron observar un patrón de derivación neural (4).

El tumor de células granulares se puede encontrar en cualquier localización, principalmente en piel, tejidos blandos y cavidad oral y, es menos común en mama, tiroides, tracto respiratorio y tracto gastrointestinal (1). Un 4-6\% de los tumores se encuentran en este último sitio anatómico y un tercio de ellos se localizan en esófago y, es el sitio más frecuente en el tracto gastrointestinal, seguido por el colon $(6,8)$.

A nivel de esófago, su ubicación más frecuente es en el tercio medio y distal (1). Además, la lesión suele posicionarse en la capa submucosa, la cual a su vez posee el plexo neuronal submucoso, reafirmando su derivación neural (9).

Puede presentarse solo, o de manera simultánea o asincrónica en varios órganos a la vez (10). Se han reportado alrededor de $5-30 \%$ de casos de tumores de células granulares múltiples $(3,10)$.
La edad de diagnóstico oscila entre los 30 y 60 años con una media de 50 años $\pm 11(6,10,11)$. $Y$ es más frecuente en mujeres que en hombres (10). La paciente tiene 21 años, por lo que escapa un poco al rango establecido, sin embargo, se ha reportado que el diagnóstico no es tan frecuente porque la mayoría de tumores de células granulares son asintomáticos y son descubiertos a la hora de realizar una endoscopía por otra razón, por lo que el diagnóstico ha ido en alza (1). Son las principales indicaciones para endoscopía: malestar o dolor epigástrico, distención abdominal, reflujo gastroesofágico y disfagia, en ese orden (10). Cuando los tumores miden más de $1 \mathrm{~cm}$, los pacientes pueden presentar disfagia (9). Y una minoría presenta reflujo gastroesofágico, dispepsia, dolor torácico, tos, náusea y ronquera (8).

A la endoscopía suelen verse, característicamente, como una masa sésil, firme, de color gris-blancuzco, o amarillo $(1,2,9)$. La paciente presenta una lesión con dichas características. A simple vista, el diagnóstico diferencial incluye leiomioma, tumor gastrointestinal de células estromales (GIST) y menos frecuentes, lesiones quísticas, otras neoplasias primarias y metástasis. Por esta razón, es necesaria la toma de biopsias, para valorar la histología de la lesión y establecer un diagnóstico certero (1,3). Cuando la histología no es de ayuda para diferenciarlos, la inmunohistoquímica puede ser útil, ya que el tumor de células granulares es negativo para CD117, CD34, descartando con estas tinciones un GIST y es negativo también para desmina y actina de músculo liso (SMA) descartando un leiomioma $(1,12)$.

La inmunohistoquímica permite dilucidar un poco el origen real de esta clase de tumores. 
Se ha señalado como primera teoría que los tumores provienen de las células de Schwann, porque se ha observado la presencia de gránulos y filamentos verticilados similares estructuralmente a los axones en los tumores granulares. Se ha descrito que, los gránulos citoplasmáticos de los tumores de células granulares pueden representar mielina alterada, o productos metabólicos de esta y además presentan resistencia a PAS diastasa (4).

Otra teoría más reciente, indica que pueden provenir de células neuroendocrinas. La literatura demuestra que la mayoría de pacientes tienen inmunohistoquímica positiva para S-100 y vimentina, correlacionando con un origen en las células de Schwann. Sin embargo, se ha observado también que algunas de las células pintan débil para PGP9.5 y ENE indicando un origen neurocrino (13).

La paciente presentaba positividad para S-100 y PAS diastasa resistente, al igual que lo reportado en la literatura.

Usualmente presenta un comportamiento benigno, pero un $0.5-2 \%$ de los tumores se consideran malignos, teniendo una mortalidad de $40 \%$, con una alta tasa de recurrencia y metástasis (5). Las metástasis más frecuentes son a nódulos linfáticos y pulmón, pero también se han descrito metástasis hepáticas $(7,16)$. Fanburg-Smith et al. describieron en 1988, seis criterios histológicos que sugieren malignidad en tumores de células granulares. Los criterios eran necrosis, "spindling", núcleo vesicular con nucléolo grande, alta proporción núcleocitoplasma, actividad mitótica aumentada (más de 2 mitosis por 10 campos a un aumento de 200x) y pleomorfismo. Si cumple con tres criterios se clasifica como maligno. Si cumple dos se considera atípico. Si solo tiene pleomorfismo y ninguno de los otros criterios se clasifica como benigno (5,7). En el 2001, utilizaron esos criterios para correlacionar los hallazgos histológicos con la clínica y encontraron que los pacientes que según Fanburg-Smith et al. se clasificaban como malignos si tenían un comportamiento maligno, mientras que los demás tumores que no calzaban en los criterios presentaban un comportamiento benigno $(5,17)$. teniendo así una buena correlación hoy día para diferenciar posibles tumores malignos.

El marcador de proliferación, Ki67, no logra indicar de manera confiable si un tumor tiene potencial de recurrencia(14).

El ultrasonido endoscópico, por otra parte, también juega un papel muy importante en la valoración de estos tumores puesto que, permite definir el tamaño del tumor y la profundidad (si alcanza submucosa o la capa muscular) para así poder guiar la terapia adecuada $(8,12)$. Se ha utilizado la resección endoscópica para los tumores submucosos y la resección quirúrgica para los que penetran hasta la capa muscular $(8,9)$. Se ha reportado el sangrado durante el procedimiento, pero no representa una complicación mayor $(1,8)$.

\section{CONCLUSIÓN}

El tumor de células granulares usualmente es benigno y puede presentarse en cualquier localización, incluyendo el esófago. El caso presentado constituye un caso típico de tumor de células granulares esofágico de carácter benigno, tanto a nivel macroscópico como histológico e inmunohistoquímico. A pesar de ser infrecuente, constituye un diagnóstico diferencial a tomar en cuenta, al observar lesiones esofágicas. 


\section{CONFLICTOS DE INTERÉS}

No existe ningún conflicto de interés.

\section{AGRADECIMIENTO}

Al servicio de Patología del Hospital Escalante Pradilla por el aporte de las imágenes histológicas

\section{REFERENCIAS BIBLIOGRÁFICAS}

1. Ling N Guifang X Hongyan W Qin H Qi S Xiangshan F. Granular cell tumor of the esophagus: a clinicopathological study of 31 cases. Int J Clin Exp Pathol. 2014;7(7):4000-4007.

2. Galanopoulos M Liatsos C Nakos G Kalafatis E. Abrikossoff Cell Tumor of the Esophagus: Case Presentation of a Rare Endoscopic Entity and Review of Literature. J Gastrointest Canc. 2015; 46:87-89.

3. Zhong N Katzka D Smyrk T Wang K Topazian M. Endoscopic diagnosis and resection of esophageal granular cell tumors. Diseases of the Esophagus. 2011; 24:538-543.

4. Fisher E Wechsler H. Granular Cell Myoblastoma-A Misnomer Electron Microscopic and Histochemical Evidence Concerning Its Schwann Cell Derivation and Nature (Granular Cell Schwannorna). Cancer. 1962; 15:936-943.

5. Singh V Gunasagaran J Pailoor J. Granular cell tumour: malignant or benign? Singapore Med J. 2015;56(9):513-517.

6. Soyeon A Jaejung J Kwangseon $\mathrm{M}$ et al. Granular cell tumor of the gastrointestinal tract: histologic and immunohistochemical analysis of 98 cases. Human Pathology Elsevier. 2015; 46:813-819.

7. Prarthana C Kingsley P Singh H Kanwardeep K Rathore S Charan K. Large mid-esophageal granular cell tumor: benign versus malignant. Rare Tumors. 2015; 7:5772.

8. Wen shu C Xiao ling Z Long J Xiao jie P Ming fan Y. Novel Diagnosis and Treatment of Esophageal Granular Cell Tumor: Report of 14 Cases and Review of the Literature. Ann Thorac Surg. 2014; 97:296-302.

9. Nakajima M Kato $\mathrm{H}$ Muroi $\mathrm{H}$ Sugawara $\mathrm{A}$ et al. Esophageal granular cell tumor successfully resected by endoscopic submucosal dissection. Esophagus. 2011; 8:203-207. 
10. Zhang M Sun Z Zou X. Esophageal granular cell tumor: Clinical, endoscopic and histological features of 19 cases. Oncology letters. 2014; 8: 551-555.

11. Singhi A Montomery E. Colorectal Granular Cell Tumor: A Clinicopathologic Study of 26 Cases. Am J Surg Pathol. 2010; 34:1186-1192.

12. Wang $\mathrm{H}$ Liu A. Esophageal granular cell tumors: Case report and literature review. World $\mathrm{J}$ Gastrointest Oncol. 2015; 7(8): 123-127.

13. Haikal F Maceira J Dias E Ramos e Silva M. Histogenesis of Abrikossoff tumour of the oral cavity. Int J Dent Hygiene 2010; 8:53-62.

14. Le B Boyer P Lewis J Kapadia S. Granular Cell Tumor Immunohistochemical Assessment of Inhibin-a, Protein Gene Product 9.5, S100 Protein, CD68, and Ki-67 Proliferative Index With Clinical Correlation. Arch Pathol Lab Med. 2004; 128:771-775.

15. Fontes A Blohem I Jipso de Souza J Santana L Guimaraes R Boente P. Granular cell tumor of anal border. J Coloproctol. 2016; 36(2):115-118.

16. Wierczorek $\mathrm{T}$ Krane $\mathrm{J}$ Domanski $\mathrm{H}$ et al. Cytologic Findings in Granular Cell Tumors, with Emphasis on the Diagnosis of Malignant Granular Cell Tumor by Fine-Needle Aspiration Biopsy. Cancer Cytopathol. 2001; 93:398-408.

17. Hwahn Kahng D Ha Kim G Youn Park D et al. Endoscopic resection of granular cell tumors in the gastrointestinal tract: a single center experience. Surg Endosc. 2013; 27:3228-3236. 